\title{
VIABILIDADE DA IRRIGAÇÃO SUPLEMENTAR NA FASE INICIAL DE DESENVOLVIMENTO DA CANA-DE-AÇÚCAR (SACCHARUM SSP.) EM REGIÕES COM DÉFICIT HÍDRICO ${ }^{1}$
}

CINTRA, José Eduardo V. ${ }^{2}$

FERREIRA, Geraldo Henrique ${ }^{2}$

BRASIL, René P. Camponez do ${ }^{3}$

Recebido em: 2008-09-08

Aprovado em: 2008-09-17

ISSUE DOI: 10.3738/1982.2278.141

RESUMO: Com posição de destaque no agronegócio brasileiro, a cana-de-açúcar vem se expandindo para novas áreas agrícolas, antes não tradicionais. Essa expansão vem ocorrendo principalmente nas regiões de cerrado, onde o período de déficit hídrico é mais acentuado. Para que o crescimento do setor sucroalcooleiro seja mantido em condições rentáveis, ele deve ser amparado não apenas na ampliação das áreas agrícolas, mas também no aumento de produtividade. O uso da irrigação, nessas áreas, constitui um alternativo potencial para a viabilidade econômica da cultura, devido ao ganho de produtividade proporcionado. Uma alternativa que vem se mostrando promissora é o uso da irrigação suplementar. Com a utilização desse sistema, é possível economizar na aplicação de água, pois pode suspender a irrigação até cinco meses antes da colheita. Além disso, obtêm-se ganhos diretos e indiretos com incremento de produtividade, longevidade e redução de custos de tratos culturais. Diversos autores concluíram que uma irrigação suplementar na fase inicial do desenvolvimento da cana de açúcar é crucial para o aumento da produtividade, principalmente na cana soca. Esses autores ressaltam também, a importância de mais pesquisas sobre a responsividade e função de produção de variedades de cana-de-açúcar à irrigação nas diversas localidades produtoras.

Palavras- chave: Cana-de-açúcar. Irrigação. Aumento de produtividade.

SUMMARY: With a prominence position in brazilian agrobusiness, the sugar-cane culture has been developed in new agricultural areas, not traditional before. That expaqnsion mainly happens in the region called cerrado, where the long dry season is larger. For keeping the development of Alcohol-sugar industry in profitable conditions, it must be, sustained by the enlargement of the agricultural areas and, also, by the increase of productivity. The use of irrigation, in those areas, is a potential alternative for economic viability of the culture, because of the productivity profity provided. One alternative that shows to be promising is the use of supplement irrigation. Using this system, it's possible to save in water applying, because it's possible to interrupt the irrigation five months before the harvest. Morreover, direct and indirect profits are adrieved with increase of productivity, longevity and reduction of cultural treatment costs. Many writers concluded that supplement irrigation used in initial stage of devepment of sugar-cane is decisive for the increase of productivity, mainly, for sprouted-cane. These authors also emphasize the importance of more researches about response and function of diversities of sugar-cane production to irrigation in the diverse procuctive localities.

Keywords: Sugar-cane. Irrigation. Increase of productivity.

1 Trabalho entregue como parte das exigências do curso de Pós-graduação em Gestão e Tecnologia Sucroalcooleira. FAFRAM - Faculdade Dr. Francisco Maeda/ FE. Rodovia Jerônimo Nunes Macedo Km 01, CEP 14500-000, Ituverava-SP

2 Engenheiro Agrônomo Estudante do curso de Pós-graduação em Gestão e Tecnologia Sucroalcooleira. FAFRAM. E-mail: jkvilela@yahoo.com.br; geraldohferreira@yahoo.com.br.

3 Professor de Irrigação e Drenagem da FAFRAM. E-mail: rpcbrasil@,hotmail.com. 


\section{INTRODUÇÃO}

A corrida contra o aquecimento global tem feito com que o a civilização procure novas fontes de energia que sejam renováveis e menos poluentes. Uma alternativa contra esse aquecimento é a utilização dos biocombustíveis, e, dentre esses, o etanol tem um destaque especial, porque pode ser produzido a partir de diversas matérias primas, como o milho, a canade-açúcar e a celulose.

No Brasil, a cana-de-açúcar assume uma posição de grande importância, por se tratar de uma cultura que ocupa amplas extensões territoriais e elevada expressividade econômica no agronegócio brasileiro. Devido à atratividade do mercado de energia alternativa e do carro flex, o setor canavieiro vem sofrendo expansão no mercado doméstico e no mercado mundial, o que, em termos macroeconômicos, significa um aumento de investimento no setor sucroalcooleiro, proporcionando uma maior geração de renda de mão-de-obra.

Com a estimativa de produção da safra 2007/2008 entre 558,1 e 579,8 milhões de toneladas, o Brasil continua sendo o maior produtor de cana-de-açúcar do mundo, seguido pela Índia e China. Com a confirmação dessa estimativa de 2007/2008, teremos um aumento de $11,3 \%$ a $15,6 \%$ do volume obtido na safra passada, ou seja, uma quantidade adicional de 56,6 a 78,2 milhões de toneladas de cana, CONAB, (2008). Essa expansão canavieira gera um deslocamento da cultura de regiões antes tradicionais para regiões que, até então, tinham pouca expressão no setor sucroalcooleiro, dando destaque para o Triângulo Mineiro, Goiás e Mato Grosso do Sul.

A utilização pela cana de $10 \%$ da área, que antes, era ocupada pela pecuária, poderá Doorenbos e Kassam (1979) dobrar a produção de cana-de-açúcar. Segundo o (CTC), Centro de Tecnologia Canavieira, as novas fronteiras para o plantio são o Maranhão, Minas Gerais, Tocantins, Mato Grosso e Bahia. No entanto, para que o crescimento do setor seja mantido em condições rentáveis, ele deverá ser apoiado, não apenas na ampliação das áreas agrícolas, mas também no aumento da produtividade.

Segundo dados de estudo do ISPN (Instituto Sociedade, População e Natureza), o cerca de 142 mil hectares de cerrado foram ocupados por canaviais na safra de 2006/2007. Essas áreas de cerrado da região centro-oeste possuem períodos com déficits hídricos mais acentuados, variando a precipitação anual de 800 a $2.000 \mathrm{~mm}$, num clima sazonal, caracterizado por chuvas e um período seco que vai de 4 a 7 meses, dependendo da região (ASSAD; ASSAD, 1999). Nesses casos, a irrigação pode ser fundamental e economicamente viável, principalmente por meio do uso de métodos mais eficientes.

A finalidade básica da irrigação é proporcionar água às culturas de maneira a atender as exigências hídricas durante todo o seu ciclo, possibilitando altas produtividades e produtos de boa qualidade; sendo que a quantidade de água necessária às culturas é função da espécie cultivada, do local de cultivo, do estágio de desenvolvimento da cultura, do tipo de solo e da época de plantio (BERNARDO, 2008). 
A agricultura irrigada exige investimento em obras, aquisição de equipamentos, transporte, controle e distribuição de água, gastos com energia e mão-de-obra. Para Clark et al (1993), esse aumento nos custos de investimento deve ser pago pelo incremento de produtividade, proporcionado pelo fornecimento eficiente de água às plantas. Soares et al (2003), em seu estudo, consideraram que, para a região do semi-árido, o uso da irrigação, na cultura da canade-açúcar, constitui-se numa alternativa potencial para o sucesso da produção sucroalcooleira. De acordo com Matioli (1998), praticamente toda a cana-de-açúcar produzida em São Paulo é cultivada em condições de sequeiro. Dentro deste panorama, insere-se a tecnologia de irrigação da cana-de-açúcar como alternativa para contribuir com a qualidade total da produção sucroalcooleira, desde que estudos e pesquisas sejam desenvolvidos, a fim de comprovar a viabilidade econômica da introdução dessa tecnologia.

A irrigação se justifica como recurso tecnológico indispensável ao aumento da produtividade das culturas em regiões onde a insuficiência ou má distribuição das chuvas inviabiliza a exploração agrícola, principalmente em algumas áreas não tradicionais. No nordeste, segundo Silva (2002), a irrigação da cana-de-açúcar, usada como prática suplementar vem sendo cada vez mais utilizada pelos produtores, devido à queda na produção de cana-deaçúcar, decorrente das baixas precipitações ocorridas no nordeste brasileiro, nos últimos anos.

Scardura e Rosenfeld (1987) afirmaram que o consumo de água da cultura da cana-deaçúcar varia em função do ciclo da cultura (cana planta ou cana soca), do estágio fenológico, das condições climáticas e de outros fatores, como água disponível no solo e variedades. Segundo Doorenbos e Kassam (1994), uma umidade adequada, durante todo o período de crescimento, é importante para se obter rendimentos máximos, visto que o crescimento vegetativo é proporcional à água transpirada.

De acordo com Matioli (1998), os benefícios da irrigação na cultura da cana-de-açúcar se dividem em benefícios diretos e benefícios indiretos. Os benefícios diretos consistem nos aumentos de produtividade agrícola e longevidade das soqueiras, enquanto os benefícios indiretos são aqueles relacionados com a redução de custos no processo produtivo agrícola, proporcionados pelo aumento de produtividade. Entretanto a viabilidade econômica é um fator indispensável para sua adoção entre os agricultores (FRIZZONE et al., 1994).

Com base nos altos custos, alguns produtores preferem utilizar a irrigação somente nas fases ficológicas mais sensíveis ao déficit hídrico ou em plantios realizados em épocas de menor índice de precipitação. Essa prática é chamada de Irrigação Suplementar ou de Salvamento.

\section{EXIGÊNCIAS HÍDRICAS DA CANA-DE-AÇÚCAR}

A cana-de-açúcar é uma planta semi-tropical perene, sofrendo, portanto, as influências do clima em todo o curso do ano, ao contrário das culturas anuais que sofrem influências em períodos limitados. Os parâmetros climáticos mais atuantes na produtividade de cana-de-açúcar 
na região Centro-sul são: Temperatura média anual; Deficiência hídrica anual; Evapotranspiração anual.

A cultura da cana-de-açúcar, para ser explorada economicamente com o objetivo de produção de sacarose, necessita de um mínimo de calor durante o ciclo vegetativo. Essa disponibilidade térmica, em termos de evapotranspiração potencial, segundo Camargo et al (1999), corresponde a cerca de $850 \mathrm{~mm}$ anuais, que é considerado limite mínimo para as exigências térmicas anuais de cultura, que corresponde, aproximadamente, à isoterma de $19^{\circ} \mathrm{C}$. A uma temperatura média diária de $21^{\circ} \mathrm{C}$, verifica-se uma elevada taxa de crescimento, enquanto que temperaturas abaixo de determinados limites reduzem, substancialmente, o crescimento da cana, sendo que este se torna insignificante para temperaturas médias diárias inferiores a $15,5^{\circ} \mathrm{C}$. Em zonas sujeitas ao fenômeno da geada, devem ser evitados os terrenos baixos, de difícil circulação de ar.

Ao ponderarmos sobre as condições hídricas para o cultivo da cana, temos que levar em conta que não é o total de precipitação anual o mais importante, mas sim, a sua distribuição ao longo do ano ou, ainda melhor, a disponibilidade de água no solo à disposição da planta durante o ciclo vegetativo. Um regime hídrico em que não ocorrem déficits hídricos é contraindicado para a cultura da cana-de-açúcar, por ser necessária a existência de um período seco, que favoreça a maturação em detrimento do crescimento. Por outro lado, quando a deficiência hídrica anual ultrapassa determinados limites, o desenvolvimento da planta poderá ficar seriamente comprometido.

Para Bernardo (2008), o consumo diário de água pela cana-de-açúcar nas principais regiões produtoras do país, depende da variedade, do estágio de desenvolvimento da cultura, da demanda evapotranspirométrica em função do mês e da região, em geral, tem variado de 2,0 a $6,0 \mathrm{~mm} / \mathrm{dia}$.

Zink et al (1978) considera que a precipitação de $1200 \mathrm{~mm}$ anuais bem distribuídos é suficiente para o bom desenvolvimento da cana, e Oliveira et al (2002) informa que um mínimo de $850 \mathrm{~mm}$, no período vegetativo, é suficiente para seu bom crescimento. Para Doorenbos e Kassam (1994), o consumo anual de água pela cultura fica entre 1500 e $2500 \mathrm{~mm}$, variando conforme a localização, clima, variedades e solo.

A freqüência e a lâmina de irrigação devem variar com os períodos de crescimento da cana. Durante o período de estabelecimento, incluindo a emergência e o estabelecimento das plântulas, é preferível efetuar aplicações de irrigação leves e freqüentes. No período vegetativo inicial, o perfilhamento é diretamente proporcional à freqüência de irrigação. Um perfilhamento vigoroso, no início, é ideal porque proporciona o surgimento de brotos aproximadamente da mesma idade.

Os primeiros estágios de desenvolvimento (emergência e perfilhamento) da cana-deaçúcar são os que mais sofrem prejuízos, pois são mais sensíveis ao déficit hídrico. Os estágios intermediários (desenvolvimento) respondem à lâmina de irrigação, mas o déficit hídrico não causa tantos prejuízos à produtividade quanto os primeiros: portanto, o intervalo de irrigação 
pode ser ampliado, porém a lâmina de água deve ser aumentada. Com um suprimento adequado de água, esse estágio é atingido rapidamente e a altura final da cana também é maior.

Já o último estágio (maturação) responde positivamente ao déficit hídrico, embora o consumo diário de água seja maior nos estágios intermediários do que nos iniciais. Isso ocorre em função do maior índice de área foliar do estágio intermediário. Os valores de Kc para a cana- de- açúcar variam de 0,55 a 1,05 de acordo com Doorenbos e Kassam (1994). Essa variação depende da fase na qual a cultura se encontra.

A cultura da cana-de-açúcar é exigente em água. Um colmo completo se compõe de 70 a $75 \%$ de parte liquida, e 25 a 30\% de sólido. Para cada 250 partes de água absorvida, apenas uma parte é retida pela matéria seca, sendo o restante, perdido. Sabe-se que, para a formação de 1 quilo de açúcar, a cultura perde em média de 900 a 920 quilos de água. (SOUZA, 1975).

Apesar de sua exigência em água, a cana não se adapta bem a solos de baixadas úmidas (hidromórficos e aluviais mal drenados). Os solos encharcados não possuem aeração suficiente para o seu desenvolvimento, dificultando o crescimento do sistema radicular e a assimilação dos nutrientes. Quando excessivamente úmidos, chegam a ocasionar a morte das plantas.

Segundo Scardua (1982), os resultados das pesquisas mostram que a cana necessita de $3,4 \mathrm{~mm} /$ dia de água como consumo médio, e, no inverno, este consumo atinge $2 \mathrm{~mm} / \mathrm{dia}$. A distribuição pluviométrica irregular na região sudeste do Brasil tem evidenciado que a cana se ressente de falta de água no período de estiagem mais prolongado, mostrando que a irrigação seria indicada como prática suplementar à água das chuvas.

\section{IRRIGAÇÃO SUPLEMENTAR}

Segundo Santos eFrizzone(2006), a irrigação suplementar consiste em suprirparcialmente a deficiência hídrica da soqueira nos primeiros estágios de desenvolvimento, sendo, na fase inicial do desenvolvimento da cultura, que se observam as maiores perdas de produtividade devido ao estresse por falta de água. Para amenizar essas perdas, a irrigação suplementar é iniciada logo após o corte e interrompida no fim do primeiro estágio de desenvolvimento da soqueira.

Como em algumas regiões do centro oeste prevalecem baixas precipitações ao longo de vários meses, durante o ciclo da cultura, torna-se essencial a utilização de novas técnicas, como a irrigação suplementar, complementar ou de salvamento, para a melhoria do cultivo.

No caso da cana-de-açúcar, o efeito do déficit hídrico sobre a produtividade varia durante o ciclo da cultura. Doorenbos e Kassam (1979) quantificaram empiricamente o efeito da água sobre a planta e estabeleceram um fator de correlação entre a produtividade e a evapotranspiração, que foi definido como fator do efeito da água sobre o rendimento. Estes autores constataram que o efeito da água sobre o rendimento da cultura, correspondente à terceira fase (período de maturação), teve baixa influência sobre a produtividade. Rosenfeld, Leme (1984), estudando 
épocas de irrigação em cana-de-açúcar no Estado de São Paulo, concluíram que as maiores reduções da produtividade ocorreram com deficiências hídricas nos primeiros oito meses do ciclo da cana planta. Com base na análise de diferentes períodos do ciclo da cultura, Scardua (1985) observou que, no primeiro período de produção (brotação, perfilhamento e estabelecimento), a redução na produtividade foi maior que no segundo (produção vegetativa), e que, no terceiro (maturação), o efeito do déficit poderia ser considerado insignificante. De acordo com o autor, o déficit hídrico nas primeiras fases pode acarretar um pior desenvolvimento radicular e baixo perfilhamento, resultando, portanto, num baixo aproveitamento da água e nutrientes disponíveis nos períodos posteriores. Vazquez (1970) citado por Rosenfeld (1989), estudando épocas de irrigação de cana-de-açúcar em Porto Rico, observou o mesmo comportamento e recomendou que, para as diversas condições climáticas, é possível economizar até $250 \mathrm{~mm}$ de água/ano, suspendendo a irrigação cinco meses antes da colheita, sem redução na produção.

Matioli et al. (1998) verificou que, na região de Ribeirão Preto - SP, durante o primeiro estágio de desenvolvimento da cultura (estabelecimento mais período vegetativo inicial), com lâmina mensal de até $30 \mathrm{~mm}$, a irrigação complementar proporcionou aumento de produtividade em até 30,4 t ha-1 para as socas de início, até meados de safra (maio a julho), enquanto, para as socas de fim de safra (setembro a novembro), o aumento de produtividade foi bastante reduzido, em torno de 3,2 a 8,4 tha-1. Oliveira et al. (2002), trabalhando também com irrigação complementar, observou em Paracatu, noroeste de Minas Gerais, produtividade média de 250 toneladas por hectare de matéria natural (folhas e ponteiros) em dois cortes.

Santos e Frizzone (2006), em um estudo de modelo de análise de decisão de uso de irrigação suplementar da cana-de-açúcar no litoral sul do Estado de Alagoas, utilizaram uma evapotranspiração de $60 \mathrm{~mm}$ mês $^{-1}$ (74\% da maior lamina estimada para o período), durante as fases de brotação e estabelecimento da soqueira, que foi de janeiro a abril. Os autores avaliaram a viabilidade econômica dessa técnica levando em consideração os benefícios diretos (aumento da produtividade, longevidade do canavial) ou indiretos (redução dos custos de plantio e redução dos tratos culturais) e concluíram que há um ganho enorme de potencial econômico e técnico de utilização da irrigação suplementar para essa localidade.

Frizzone et al (2001), em um estudo de viabilidade econômica da irrigação suplementar da cana-de-açúcar no Norte do Estado de São Paulo, analisou o uso dessa técnica nas socas das colheitas de maio, julho, setembro e novembro, estimando um acréscimo de 28,8; 22,1; 9,8 e 5,6 t/ha para os respectivos meses. Nesse experimento, foi usada uma lâmina igual a $50 \%$ da evapotranspiração estimada. Também foi estimada a receita líquida produzida pela irrigação em cada uma dessas épocas. Com isso, os autores verificaram que a irrigação suplementar da cana soca de maio e julho, colhida desde o início até meados da safra, apresentou potencial de viabilidade técnico-econômica, podendo ser introduzido nas lavouras canavieiras da região Norte Paulista. Já para a irrigação suplementar da soca de setembro e novembro, até o final da safra, não apresentou viabilidade econômica. Segundo os autores, esses resultados podem ser explicados pelo fato de que o primeiro estádio de desenvolvimento das socas tem 
o início em meados de maio e termina em medos de agosto, época essa que coincide com o período do ano de maior deficiência hídrica nessa região. Por outro lado, o primeiro estádio de desenvolvimento das socas, de meados de setembro até o final da safra (novembro), coincide, em sua maior parte, com o período do ano de menor deficiência hídrica (outubro a março), nas condições edafoclimáticas do Estado de São Paulo. Eles também ressaltam que essa viabilidade econômica, quando comparada com a cana de sequeiro, será tão maior quanto mais pobre e com menor capacidade de retenção de água pelo solo.

Assim como Frizzone et al (2001), Santos e Frizzone (2006), observaram que essa técnica pode ser inviabilizada caso o aumento de produtividade, proporcionado pela irrigação, seja menor que $0,100 \mathrm{t} . \mathrm{mm}^{-1} \mathrm{ha}^{-1}$.

Segundo Matioli (1998), o sistema mais recomendado para irrigação suplementar da cana-de-açúcar é aquele por aspersão com autopropelido de longo alcance, dotado de aspersor tipo canhão. Por ser um sistema mecanizado e portátil, utiliza pouca mão-de-obra, o que proporciona grande flexibilidade operacional no campo. Este sistema vem sendo bastante difundido nas usinas e destilarias de todo o Brasil.

É importante salientar que, no uso de irrigação suplementar, o sistema não é dimensionado para suprir a necessidade hídrica total da cultura, o que faz com que os custos iniciais de implantação dessa técnica sejam menores quando comparado com o uso de irrigação total, tornando essa técnica ainda mais viável.

\section{CONSIDERAÇÕES FINAIS}

Vários autores observaram que a fase inicial do desenvolvimento da cana-de-açúcar é a que proporciona a maior quebra na produção, quando sofre estresse hídrico. Com isso, concluíram que uma irrigação suplementar nessa fase é crucial para o aumento da produtividade, principalmente na cana soca, colhida no inicio da safra. Esse fato é mais expressivo em regiões onde a colheita coincide com um período de seca acentuada e que apresentam solos pobres e com baixa capacidade de retenção de água. Esses autores observaram que a irrigação suplementar nessas condições, culmina em uma receita liquida maior que a cana produzida em sequeiro. Esse aumento na receita foi provocado pelos benefícios diretos e indiretos da irrigação e não só pelo aumento de produtividade. Entretanto muitos dos autores ressaltam a importância de mais pesquisas sobre a responsividade e função de produção de variedades de cana-de-açúcar sujeitos à irrigação nas diversas localidades produtoras. 


\section{REFERÊNCIAS}

ASSAD E.; LOPES ASSAD, M. L. Cerrado brasileiro: possibilidades e alternativas para produção e preservação. Brasília, texto de subsídio para a preparação da Agenda 21 no item Agricultura Sustentável, mimeo, 1999.

BERNARDO, S. Manejo da irrigação na cana- de- açúcar. Disponível em: $<$ http://www.agronegocio.goias.gov.br/docs/portal/seminarioIII.pdf $>$. Acesso em 15 maio 2008.

CAMARGO, M. B. P. et al. Modelo agrometeorológico de estimativa de produtividade para laranja Valência. Bragantia, Campinas, v. 58, n. 1, p. 171-178, 1999.

CLARK, E; JACOBSON, K; OLSON, D. C. Avaliação econômica e financeira de projetos de irrigação. Brasília: Ministério da Integração Nacional/Secretaria da Irrigação, 1993. (Manual de irrigação, 3).

CONAB-Companhia Nacional de Abastecimento. Primeiro levantamento. Disponível em: $<$ http://www.conab.gov.br> . Acesso em: abr. 2008.

CTC- Centro de Tecnologia Canavieira. www.ctcanavieira.com.br Acesso em abr. 2008

DOORENBOS, J; KASSAM, A. H. Efeitos da água no rendimento das culturas. Campina Grande: Universidade Federal da Paraíba, 1994. p, 223-226.

DOOREMBOS, J. \& KASSAM, A.H.. Efeito da água no rendimento das culturas, Estudos FAO Irrigação e Drenagem . Série n.33 , p. 42-53. 1979.

FRIZZONE, J. A. et al, Viabilidade econômica da irrigação suplementar da cana-de-açúcar (Saccharum spp), para a região Norte do Estado de São Paulo. Acta Scientiarum, Maringá, v. 23, n. 5, p. 1131-1137, 2001.

FRIZZONE, J. A; BOTREL, T. A; FREITAS, H. A. C. Análise comparativa dos custos de irrigação por pivô-central, em culturas de feijão, utilizando energia elétrica e óleo diesel. Engenharia Rural, Piracicaba, v.5, n.1, p.34-53, jul. 1994.

ISPN - Instituto Sociedade, População e Natureza .www.ispn.rog.br. Acesso em abr de 2008.

MATIOLI, C. S. Irrigação suplementar de cana-de-açúcar (Saccharum ssp) ciclo cana soca: um modelo de análise de decisão para o Estado de São Paulo. 1998. 98p. Tese (Doutorado em Agronomia). Escola Superior de Agricultura “Luiz de Queiroz”, Universidade de São Paulo, Piracicaba. 
OLIVEIRA, M. W. et al. Avaliação do potencial produtivo de sete variedades de cana-de-açúcar sob irrigação complementar. In: REUNIÃO BRASILEIRA DE FERTILIDADE DO SOLO, 25., Rio de Janeiro, 2002. Anais... Rio de Janeiro: SBCS. CD-ROOM.

ROSENFELD, U. Determinação do período critico de deficiência hídrica para a cultura da cana-de-açúcar (Saccharum ssp). 1989. 88p. Dissertação (Mestrado em Agronomia). Escola Superior de Agricultura “Luiz de Queiroz”, Universidade de São Paulo, Piracicaba.

ROSENFELD, U; LEME, F. J. A. Produtividade da cana-de-açúcar irrigada por aspersão: estudo de época de irrigação. In: CONGRESSO NACIONAL DA STAB, 3. Anais... São Paulo: STAB, 1984. p 77-84.

SANTOS, M. A. L; FRIZZONE, J. A. Irrigação suplementar da cana-de-açúcar (Saccharum $s s p$ ) colhida no mês de janeiro: um modelo de análise de decisão para o litoral sul do estado de Alagoas. Irriga, Botucatu, v.11, n. 3, p. 339-335, jul-set, 2006.

SCARDUA, R. O clima e a irrigação na produção agro-industrial da cana-de-açúcar (Saccharum ssp). 1985, 122p. Tese (Livre Docência). Escola Superior de Agricultura "Luiz de Queiroz”, Universidade de São Paulo, Piracicaba.

SCARDUA, R; ROSENFELD, U. Irrigação de cana-de-açúcar. In: CANA-de-açúcar: cultivo e utilização. Campinas: Fundação Cargil, 1987. v.1, p. 373-431.

SILVA, A. B. Resposta da cana-de-açúcar irrigada sob diferentes níveis de adubação. 2002. 61p. (Dissertação de Mestrado). Universidade Federal de Campina Grande/Paraíba.

SCARDUA, R. Irrigação em cana-de-açúcar: aspectos técnicos e econômicos. Álcool \& Açúcar. São Paulo, v.2, n.5 - p. 26-36, 1982.

SOARES, J. M. et al. Agrovale, uma experiência de 25 anos em irrigação da cana-de-açúcar na região do Submédio São Francisco. ITEM, Brasília, n.60, p.55-64, 2003.

SOUZA, J. A. G .C. - À irrigação por aspersão na cultura da cana-de-açúcar - RJ, Brasil Açucareiro, v. 85, n.2, p. 27-35, 1975.

ZINK, F; GONÇALVES, R ; PASSOS, S, M. Cultura de cana-de-açúcar. Secretaria da Agricultura do Estado de São Paulo, 15p, 1978. (Boletim técnico, n. 121) 